\title{
Evaluation and standardization of growth stage of wheat against spot blotch caused by Bipolaris sorokiniana
}

\section{Authors Info}

Deepshikha*, B. Kumari and E. Premabati Devi

Department of Plant Pathology, G.B. Pant University of Agriculture and Technology, Pantnagar-263 145, India

${ }^{*}$ Corresponding Author Email : deeppatho@rediffmail.com

Key words

Bipolaris sorokiniana

Double digit scale,

Crop growth stage,

Spot blotch

Publication Info

Paper received : 03.10 .2015

Revised received: 07.01.2016

Re-revised received : 20.07.2016

Accepted: 13.07 .2016

\section{Abstract}

Aim: Spot blotch caused by Bipolaris sorokiniana (Sacc.) Shoem being a major disease of wheat in warm and humid regions of the world with a worldwide distribution pose a thrust area for sustaining wheat productivity. The pathogen is most aggressive under high relative humidity and temperature associated with the low fertility of soils leading to reduction in grain weight and yield. It is the major biotic constraint in wheat mainly in the Gangetic plains, especially in the rice-wheat cropping system as rice serves as a host for the pathogen and provides favourable environment for its survival and multiplication. Losses due to spot blotch disease depends on the level of resistance in a cultivar and prevailing weather conditions. The present study aimed to determine the crop growth stage of wheat at which recording of disease was most strongly related to the severity of spot blotch for efficient selection of resistant genotypes.

Methodology: Field trials were conducted to study the response of twenty one wheat genotypes against spot blotch under epiphytotic conditions during 2006-07 to 2011-12 crop seasons at Norman E. Borlaug Crop Research Centre of G. B. Pant University of Agriculture and Technology, Pantnagar. The disease severity was assessed at three different growth stages (GS) viz. GS 55 (half of inflorescences emerged), GS 75 (medium milk) and GS 87 (hard dough) on Zadoks scale (Zadoks et al., 1974) following the method proposed by Singh and Kumar (2005) on Double digit scale (0-9)

Results: The results indicated that the best stage to record the disease was medium milk (GS 75) and not GS 55 (half of inflorescences emerged), or dough stage (GS 87) for accurate assessment of resistance level.

Interpretation: Varieties like HD2888, HS375, PDW291, VL804, VL829, WH1021 and $\mathrm{WH} 1105$ were highly resistant to spot blotch.

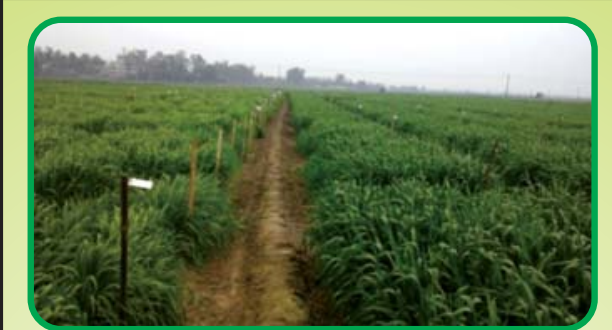

Screening of varieties at field condition

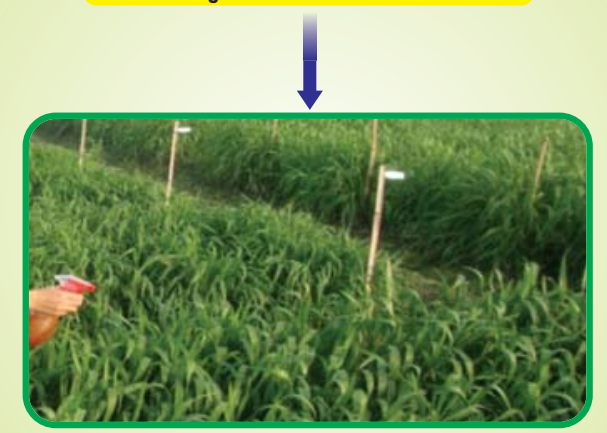

Pathogen inoculation $\left(10^{5}\right.$ spores $\left./ \mathrm{ml}\right)$

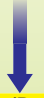

Disease assessment (Double digit scale 0-9)
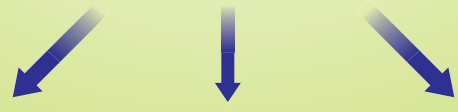

GS 55 (stage) GS 75 (stage) Best stage GS 87 (stage) 


\section{Introduction}

Spot blotch caused by Bipolaris sorokiniana is an important disease of wheat and triticale in India, especially in North Eastern Plain Zone (NEPZ) and other South Asian countries due to prevalence of hot and humid weather conditions. Further, wide spread use of conservation tillage practices may also be favorable for spot blotch incidence in the South East Asia (Duveiller and Sharma, 2009).

Spot blotch causes small, dark-brown, round to oblong lesions ranging 1 to $2 \mathrm{~mm}$ long without chlorotic margin on leaves of wheat plants. In susceptible genotypes, these lesions extend very quickly in oval to elongated blotches, light brown to dark brown in color and may reach several centimeters before coalescing and inducing the death of the leaf. The disease is also emerging in North Western Plain Zone (NWPZ) due to climatic changes. In India, yield loss may range from $10-50 \%$ which can be devastating for farmers in the Eastern Gangetic Plains depending on the level of resistance in a cultivar and weather conditions (Chowdhury et al., 2013).

The use of resistant cultivars is the most economical and environmentally safe way of managing the disease in field as compared to chemical (Singh et al., 2004, Singh et al., 2014 and Singh et al., 2015) and biological control (Singh et al., 2013) for poor and marginal farmers of South Asia. Considering the economic importance of spot blotch, there is an urgent need to identify and develop genetically improved germplasm for spot blotch resistance for which a large number of wheat and triticale varieties are regularly tested in India at hot spot locations under artificially inoculated conditions.

For rapid scoring of large numbers of entries, a double digit 0-9 scale has been evolved (Singh et al., 2005, Singh et al., 2003) by taking record of per cent leaf blighted due to disease in case of flag (F) and a leaf below it (F-1). Balkan et al. (2011) found major contribution of top leaves in grain filling in wheat. Disease scoring at suitable crop growth stage is crucial for better understanding of disease epidemiology and crop-loss assessments hence, important in developing the efficient disease management strategies. Wheat spot blotch is a disease of concern for 10 million ha of India, adjoining Nepal and Bangladesh. Resistance to wheat blotch is economically viable, environmentally safe and farm friendly measure to control the disease. The main objective of the present study was to invent a growth stage to record spot blotch fungus for efficient selection of blotch resistant wheat material. This parameter has not been studied clearly and in detail earlier, hence different wheat accessions were taken for the study and available scientific methodology for wheat blotch evaluation.

\section{Materials and Methods}

Plant materials and field trial : A total of two hundred and ninety genotypes of wheat (Triticum aestivum and $T$. durum) were planted in 2006-2007 at Norman E. Borlaug Crop Research Centre of G. B. Pant University of Agriculture and Technology, Pantnagar (Uttarakhand), India (Table 1). After two years (20062007 to 2007-2008), twenty one genotypes which produced more or less consistent reaction (resistance and susceptibility) with pathogen were selected and repeatedly planted for another four consecutive Rabi seasons (2008-09 to 2011-2012). These selected genotypes were promising highly productive and popularly grown in farmers' field.

Topographically, Pantnagar is located at latitude $29^{\circ} \mathrm{N}$ and longitude $79.73^{\circ} \mathrm{E}$ and at an altitude $243.84 \mathrm{~m}$ amsl in the humid, subtropical regions of North West Plain Zone (NWPZ) at the foot hills of Shivalik range of Himalayas. Each entry is planted in a single row of $2 \mathrm{~m}$ length and row of highly susceptible genotype Raj 4015, was repeat planted after every twenty test entries along with three border rows all around the block of test entries in field each year so as to create maximum inoculum pressure. The agronomic practices were carried out as recommended for raising a good crop and recommended doses of fertilizers were applied.

Field inoculation: Spot blotch was induced by inoculating a pure culture of isolates of Bipolaris sorokiniana (Kumar et al., 1999). The inoculum was multiplied on autoclaved sorghum seeds in laboratory and spores were harvested in water. Inoculations was done from tillering stage till boot leaf stage after twenty days intervals by uniformly spraying the spore suspension (approximately $10^{5}$ spores/ ml) containing surfactant Tween 20 using a handheld atomizer during the evening hours (Joshi et al., 2007a, 2007b), thus allowing proper moisture on the leaves in night and ensuring good infection. Subsequently favorable moisture conditions were maintained in field to facilitate disease development.

Disease assessment : The disease severity was assessed at three different growth stages (GS) viz. GS 55 (half of inflorescences emerged), GS 75 (medium milk) and GS 87 (hard dough) on Zadoks scale (Zadoks et al., 1974) following the method proposed by Singh and Kumar (2005) on Double digit scale (0-9) as follows:

0: No blight, 1: Up to 10\% leaf area blighted, 2: $11-20 \%$ leaf area blighted, 3: $21-30 \%$ leaf area blighted, 4: $31-40 \%$ leaf area blighted, 5: $41-50 \%$ leaf area blighted, 6: 51-60\% leaf area blighted, 7: $61-70 \%$ leaf area blighted, 8: $71-80 \%$ leaf area blighted, 9: $>80 \%$ leaf area blighted.

The left hand side digit of score represents the per cent blighted area of flag leaf $(F)$, whereas the right side digit indicates the score of blight on one leaf below flag (F-1).

The average disease score of data was calculated by averaging the figures of both digits separately and then rounding up of decimal points $0.5-0.9$ to 1 and $0.1-0.4$ to 0 . Based on the 
Table 1 : Effect of crop growth stages on spot blotch scores (pooled) of entries of wheat during 2006-07 to 2011-12 crop seasons

\begin{tabular}{|c|c|c|c|c|c|c|c|c|c|}
\hline \multirow[t]{2}{*}{ Entry } & \multicolumn{3}{|c|}{$\begin{array}{c}\text { GS } 55 \text { (half of inflorescences } \\
\text { emerged stage) }\end{array}$} & \multicolumn{3}{|c|}{ GS 75 (Medium milk stage) } & \multicolumn{3}{|c|}{ GS 87 (Hard dough stage) } \\
\hline & HS & AV & Reaction & HS & AV & Reaction & HS & AV & Reaction \\
\hline HPW 349 & 35 & 12 & $\mathrm{HR}$ & 67 & 35 & MR & 79 & 57 & MS \\
\hline HS 375 & 12 & 12 & HR & 47 & 26 & $\mathrm{R}$ & 58 & 36 & MR \\
\hline HS 490 & 46 & 13 & $\mathrm{R}$ & 68 & 46 & MR & 89 & 57 & $S$ \\
\hline VL 804 & 16 & 15 & HR & 46 & 24 & $\mathrm{R}$ & 67 & 45 & MR \\
\hline VL 829 & 24 & 12 & $\mathrm{HR}$ & 46 & 24 & $\mathrm{R}$ & 67 & 45 & MR \\
\hline VL 892 & 45 & 13 & $\mathrm{R}$ & 78 & 57 & MS & 88 & 58 & $S$ \\
\hline Raj 4015(check) & 58 & 34 & MR & 78 & 47 & MS & 99 & 67 & $S$ \\
\hline HD 3043 & 13 & 02 & $\mathrm{HR}$ & 69 & 57 & MS & 89 & 67 & $S$ \\
\hline HD 3059 & 14 & 01 & HR & 67 & 45 & MR & 89 & 57 & $S$ \\
\hline PDW 233 & 35 & 24 & $H R$ & 67 & 34 & MR & 89 & 57 & S \\
\hline PDW 291 & 12 & 12 & $\mathrm{HR}$ & 25 & 23 & $\mathrm{HR}$ & 38 & 24 & $\mathrm{R}$ \\
\hline WH 1105 & 13 & 01 & HR & 57 & 35 & R & 69 & 36 & MS \\
\hline C 306 & 13 & 13 & HR & 68 & 35 & MR & 89 & 57 & S \\
\hline WH 1021 & 35 & 13 & $\mathrm{HR}$ & 37 & 27 & $\mathrm{R}$ & 69 & 35 & MS \\
\hline HD 2888 & 12 & 12 & HR & 24 & 24 & $H R$ & 58 & 35 & MR \\
\hline HD 2932 & 45 & 44 & $\mathrm{R}$ & 78 & 46 & MS & 89 & 57 & S \\
\hline NIAW 1415 & 13 & 13 & $\mathrm{HR}$ & 58 & 46 & MR & 79 & 57 & MS \\
\hline AKDW 2997-16(durum) & 25 & 15 & $\mathrm{HR}$ & 56 & 38 & $\mathrm{R}$ & 87 & 44 & $S$ \\
\hline MPO 1215 & 36 & 13 & $\mathrm{R}$ & 78 & 46 & MS & 89 & 57 & $S$ \\
\hline KRL 19 & 35 & 23 & $H R$ & 78 & 45 & MS & 89 & 57 & $S$ \\
\hline KRL210 & 13 & 12 & $\mathrm{HR}$ & 28 & 25 & $\mathrm{HR}$ & 38 & 37 & $\mathrm{R}$ \\
\hline
\end{tabular}

HS-Highest score, AV-Average score, HR-Highly resistant, R-Resistant, MR-Moderately resistant, MS-Moderately susceptible, S- Susceptible

disease score values obtained at three different stages, the genotypes were categorized as Highly resistant (HR), resistant (R), Moderately Resistant (MR), Moderately susceptible (MS) and Susceptible (S) as following:

$\begin{array}{lll}\text { Categorization of resistance based on disease score: } \\ \text { Average score } & \text { Highest score } & \text { Category } \\ 00-13 & 35 & \text { Highly Resistant } \\ 14-35 & \text { Upto } 57 & \text { Resistant } \\ 36-57 & \text { Upto } 68 & \text { Moderately Resistant } \\ 58-69 & \text { Upto } 79 & \text { Moderately Susceptible } \\ >69 & >79 & \text { Susceptible }\end{array}$

The most appropriate stage of disease recording was assessed after comparing the data of studies over years.

\section{Results and Discussion}

The pooled spot blotch scores (HS and AV) of 21 genotypes including susceptible check, Raj 4015 at GS 55 (half of inflorescences emerged), GS 75 (medium milk) and GS 87 (hard dough) stages are presented in Table 1 along with the level of host resistance (HR, R, MR, MS and S). There were differences in terms of spot blotch scores in different genotypes at three stages.
At GS 55 (half of inflorescences emerged stage), sixteen genotypes viz. HPW 349, HS 375, VL 804, VL 829, HD 3043, HD 3059, PDW 233, PDW 291, WH 1105, C 306, WH 1021, HD 2888, NIAW 1415, AKDW 2997-16, KRL 19 and KRL 210 were highly resistant, 4 (HS 490,VL 892, HD 2932 and MPO 1215) were resistant types and one i.e., Raj 4015 was moderately resistant (MR) type.

At GS 75 (medium milk stage), three genotypes PDW 291, HD 2888 and KRL 210 were highly resistant type, six genotypes, HS 375, VL 804, VL 829, WH 1105, WH 1021 and AKDW 2997-16 were resistant type, whereas six (HPW 349, HS 490, HD 3059, PDW 233, C 306 and NIAW 1415) were moderately resistant type and six (VL 892, Raj 4015, HD 3043, HD 2932, MPO 1215 and KRL 19) were moderately susceptible type.

At GS 87 (hard dough stage), genotypes, PDW 291 and KRL 210 were resistant (R), four genotypes viz. HS 375, VL 804 , VL 829 and HD 2888 showed moderate resistance, four genotypes were HPW 349, WH 1105, WH 1021 and NIAW 1415 moderately susceptible and eleven (HS 490, VL 892, Raj 4015, HD 3043, HD 3059, PDW 233, C 306, HD 2932, AKDW 2997-16 MPO 1215and KRL 19) were susceptible types. 
From the above results it may be concluded that the medium milk stage (GS 75) in wheat was found to be the most appropriate stage to record spot blotch incidence. These results are in conformity with the findings of Wegulo et al. (2009) and Singh et al. (2014) who also reported that the best correlation of spot blotch and tan spot severity and yield from flowering to watery milk stage in case of wheat. Vergnes et al. (2006) underlined the importance of field screening for improving resistance to spot blotch in wheat and studied the Helminthosporol sensitivity on 4-leaf seedling (GS 14), booting (GS 45), anthesis completed (GS 69) and late milk grain (GS 77) stages. The level of helminthosporol $(\mathrm{HL})$ toxin sensitivity and disease severity increase between Zadok's growth stage GS 69 (anthesis completed) and GS 77 (late milk grain) which coincides with massive production of conidia on the increasing area of senescing plant tissues (Chaurasia et al., 2000, Duveiller et al., 2005), suggesting that growth stage affects host physiology. Bashyal et al. (2012) identified growth stage 75 as the most appropriate growth stage for toxin, helminthosporol infiltration and therefore, could be used for the screening of wheat genotypes in situ. Helminthosporol is major sesquiterpene toxin, produced by $B$. sorokiniana which affects membrane permeability, thereby inhibiting mitochondrial oxidative phosphorylation, photophosphorylation in chloroplasts and proton pumping across the plasma membrane, as well as $\beta-1,3-$ glucan synthase activity (Briquet et al., 1998). Abiotic factors such as senescence and force drying of leaves due to heat may not be ignored because they contributes to higher score of disease if there is a delay in recording of spot blotch in field after medium milk stage. A delay of few days (around 1 week) in the evaluation, especially when plant reaches late milk stage, can make it difficult for the evaluator to recognize a less susceptible plant from a more susceptible one. Data recording should be correlated with the growth stage of the host otherwise it may give a false note of disease severity (Chaurasia et al., 2000 and Joshi et al., 2002). From the experiment, it can be concluded that varieties like HD2888, HS375, PDW291, VL804, VL829, WH1021 and WH1105 are resistant to highly resistant to spot blotch. These could potentially be used by the breeders for developing spot blotch resistant wheat material.

\section{Acknowledgment}

Authors are thankful to the Department of Plant Pathology and University authority for providing facilities to conduct the experiment.

\section{References}

Balkan, A., T. Genctan and O. Bilgin: Effect of removal of some photosynthetic organs on yield components in durum wheat (Triticum aestivum L.). Bangladesh J. Agril. Res., 36,1-12 (2011).

Bashyal, B.M., R. Chand, L.C. Prasad and A.K. Joshi: Influence of growth stage on sensitivity to helminthosporol toxin of Bipolaris sorokiniana of barley (Hordeum vulgare). Indian J. Agric. Sci., 82,
724-6 (2012).

Briquet, M., D. Vilret, P. Goblet, M. Mesa and M.C. Eloy: Plant cell membranes as biochemical targets of the phytotoxin helminthosporol. J. Bioenerg. Biomembr., 30, 285-295(1998).

Chaurasia, S., R. Chand and A.K. Joshi: Relative dominance of Alternaria triticina Pras. Et. Prab. and Bipolaris sorokiniana (Sacc.) Shoemaker in different growth stage of wheat (T. aestivum L.). J. PI. Dis. Prot., 107, 176-181(2000).

Chowdhury, A.K., G. Singh, B.S. Tyagi, A. Ojha, T. Dhar and P.M. Bhattacharya: Spot blotch disease of wheat - a new thrust area for sustaining productivity. J. Wheat Res., 5, 1-11(2013).

Duveiller, E. and R.C. Sharma: Genetic improvement and crop management strategies to minimize yield losses in warm nontraditional wheat growing areas due to spot blotch pathogen Cochliobolus sativus. J. Phytopathol., 157, 521-534 (2009).

Duveiller, E., Y.R. Kandel, R.C. Sharma and S.M. Shrestha: Epidemiology of foliar blights (spot blotch and tan spot) of wheat in the plains bordering the Himalayas. Phytopathology, 95, 248-56 (2005).

Joshi, A.K., G. Ortiz-Ferrara, J. Crossa, G. Singh, G. Alvarado, M.R. Bhatta, E. Duveiller, R.C. Sharma, D.B. Pandit and A.B. Siddique: Associations of environments in South Asia based on spot blotch disease of wheat caused by Cochliobolus sativus. Crop Sci., 47,1071-1084 (2007a).

Joshi, A.K., G. Ortiz-Ferrara, J. Crossa, G. Singh, R. Sharma, R. Chand and R. Parsad: Combining superior agronomic performance and terminal heat tolerance with resistance to spot blotch (Bipolaris sorokiniana) in the warm humid Gangetic plains of South Asia. Field Crop Res., 103, 53-61, (2007b).

Kumar, J., A.K. Sharma, R. Kumar and S. Nagarajan: Anew technique to develop artificial epiphytotics of foliar blight in wheat (Triticum aestivum). Indian J. Agric. Sci., 69, 49-52, (1999).

Singh, D.P., R. Chand, D.S. Dodan, A. Singh, K.P. Singh, A.N. Tewari, K.M.P. Singh, S. Kaur, R.N. Singh, A.K. Singh, S.P. Singh, V.K. Singh, R.N. Brahma, I.K. Kalappanawar, V.A. Solanki, R.K. Pathak, S.K. Pant, S.Y. Das and A.K. Chowdhury: Evaluation of wheat and triticale genotypes for resistance to leaf blight caused by Bipolaris sorokiniana and Alternaria triticina. Indian Phytopath., 56,473-475 (2003).

Singh, D.P., A.K. Sharma, A.N. Tewari, K.P. Singh, A.K. Singh, R.N. Singh, S.P. Singh, I.K. Kalappanawar, D.S. Dodan and V.K. Singh: Assessment of losses due to leaf blight in popular varieties of wheat (Triticum aestivum) under different sowing conditions and agroclimatic zones in India. Indian J. Agric. Sci., 74,110-113 (2004).

Singh, D.P., A. Singh, I.S. Solanki, S.P. Singh, J. Verma, S. Mahapatra, S.K. Mukhopadhyay and S. Dutta: Management of spot blotch of wheat caused by Bipolaris sorokiniana in wheat causing fungicides. Indian Phytopath., 67, 308-310 (2014).

Singh, D.P., I.K. Kalappanavar, S.Y. Das, S.S. Karwasra, M. Meeta, A.K. Chowdhury, S. Mahapatra, S.S. Vaish, S.P. Singh, D.S. Dodan, S.K. Mukhopadhyay, S. Dutta, J. Kumar, Deepshikha, K. Srivastava, C.S. Azad, I.S. Solanki and H.C. Lal: Optimum growth stage of wheat and triticale for evaluation of resistance against spotblotch. Indian Phytopath., 67, 423-425 (2014).

Singh, D.P., I. Sharma, I. Singh, M.M. Jindal, S.K. Mann, A.K. Chowdhury, S. Mahapatra, K.P. Singh, J. Kumar, Deepshikha, K. Srivastava, S.S. Vaish, R. Chand, D.S. Dodan, S.P. Singh, J. Verma, S.Y. Das, S.S. Karwasra, A.C. Pradhan, S.K. 
Mukhopadhyay, S. Dutta, I.K. Kalappanavar, I.S. Solanki, A. Kumar, C.S. Azad and H.C. Lal: Evaluation of sources of resistance to leaf blight (Bipolaris sorokiniana and Alternaria triticina) in wheat (Triticum aestivum) and triticale. Indian Phytopath., 68, 221-222 (2015).

Singh, D.P. and P. Kumar: Method of scoring of leaf blight of wheat caused by Bipolaris sorokiniana (Sacc.) Shoem. on top two leaves at adult plant stage. In: Integrated Plant Disease Management (Eds.: R. C. Sharma and J. N. Sharma). Scientific Publishers (India), Jodhpur, pp. 289-294 (2005).

Singh, N.K., F.K. Chaudhary and D.B. Patel: Effectiveness of
Azotobacter bio-inoculant for wheat grown under dryland condition. J. Environ. Biol., 34, 927-932 (2013).

Vergnes, D.M., M.E. Renard, E. Duveiller and H. Maraite: Effect of growth stage on host sensitivity to helminthosporol toxin and susceptibility to Cochliobolous sativus causing spot blotch on wheat. Physiol. Mol. Plant Pathol., 68,14-21(2006).

Wegulo, S.N., J.A. Breathnach and P.S. Baenziger: Effect of growth stage on the relationship between tan spot and spot blotch severity and yield in winter wheat. Crop Protection, 28, 696-702 (2009).

Zadoks, J.C., T.T. Chang and C.F. Konzak: A decimal code the growth stages of cereals. Weed Res., 14, 415-421(1974). 